\title{
Extranodal NK/T-cell lymphoma of the nasal type with predominant T-cell markers: A rare subtype of rare disease entity
}

\section{Ankur Nandan Varshney, Rajesh Patidar, Mridul Malhotra, Monalisa Behera, Mukesh Nagar, S. P. Kataria}

Department of Medical Oncology, Vardhman Mahavir Medical College and Safdurjung Hospital, New Delhi, India

Address for the Correspondence: Dr. Ankur Nandan Varshney, Department of Medical Oncology, Vardhman Mahavir Medical College and Safdurjung Hospital, West Ansari Nagar, New Delhi - 110 0029, India. E-mail: drankurnvarshney@ gmail.com

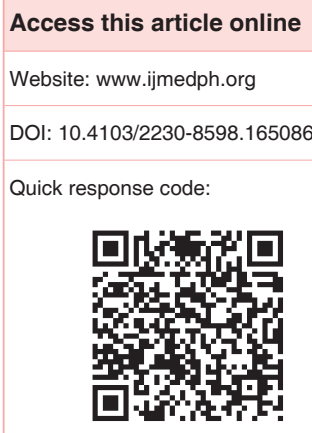

Extranodal NK/T-cell Lymphoma of nasal type is a rare and comparatively a new entry among group of Non-Hodgkin lymphomas. The disease is characterized by a clinically aggressive course with involvement of upper aero-digestive tract and classical immune-phenotyping with CD2, CD3 and CD56 positivity. Being a rare entity, treatment entities are yet not formulated in guidelines. We hereby report a case of extranodal NK/T-cell lymphoma with predominant $T$ cell markers who was initially treated with CHOP regime of non-Hodgkin lymphoma and later successfully treated with SMILE regime.

Key words: NK/T-cell lymphoma, non-Hodgkin lymphoma, SMILE regime

\section{INTRODUCTION}

Nasal type of NK/T-cell lymphoma has been recognized as a separate disease entity in the 2008 WHO classification of malignant lymphomas. ${ }^{[1]}$ It is a rare but aggressive form of extranodal form of non-Hodgkin lymphoma (NHL). It is significantly more common among Asian and Latin American population as compared to European and North American population where diffuse large B-cell lymphoma is more common at the same anatomical site. Among Asian subgroup, extranodal T/NK-cell lymphoma is more commonly reported among Chinese, Japanese and Korean ethnicity. ${ }^{[2]}$ Classically it present with involvement of upper aero-digestive tract and immune-phenotypically is classically $\mathrm{CD} 2^{+}$, cytoplasmic $\mathrm{CD}^{+}$and $\mathrm{CD}_{5} 6^{+}$. Cases of $\mathrm{CD} 2^{+}, \mathrm{CD}^{+}$but $\mathrm{CD} 56-$ ve are termed as predominant $\mathrm{T}$-cell type and distinctly rare..$^{[3]}$ Optimal treatment therapy is yet not validated. ${ }^{[4]}$ We hereby report a rare case of extranodal NHL of nasal type with predominant T-cell markers, who was refractory to CHOP regime and responding to treatment with SMILE regime. ${ }^{[5]}$

\section{CASE REPORT}

A 28-year-old male was referred to us with complaints of nasal blockage, discharge, fever and deviation of the nose since last 2 months. On examination, there was deviation of the nose toward right side along with redness and edema of overlying skin over nostrils. There was purulent discharge coming out from both nostrils [Figure 1a]. There was no lymphadenopathy or organomegaly associated with illness. He denied any history of night sweat and significant weight loss. His hemoglobin at the time of presentation $=13$, total leukocyte count $=7650$ with normal differential and platelet count $=$ 2.6 lakh with raised erythrocyte sedimentation rate $=54 \mathrm{~mm}$. Peripheral smear and bone marrow examination reported no abnormality. Serum lactate dehydrogenase $(\mathrm{LDH})$ was raised. Computed tomography scan revealed diffuse soft tissue thickening involving B/L nasal vestibule, nasal walls (left $>$ right) and nasal septum predominantly anterior part with thickening of naso-labial fold [Figure 2]. Bony architecture was intact. Positron emission tomography scan ruled out any distant metastasis and involvement of another group of lymph nodes. Biopsy of the lesion showed discrete lymphoid cells with hyper-chromatic nuclei along with large foci of tumor necrosis and vascular proliferation. Immuno-phenotyping was positive for CD2, cytoplasmic CD3, CD43 and negative for CD56 and B-cell markers [Figure 3]. Ki-67 index was significantly positive in 60-70\% cells. As Epstein-Barr virus (EBV) DNA test was not available, antibodies were tested, and the patient had high titer of 
serum IgG antibodies against EBV capsid antigen. Thus, patient as diagnosed as T2-weighted stage extranodal NK/T-cell lymphoma of nasal type with predominant T-cell markers. Initially, he was administered intravenous (iv) antibiotics to control infection, he was administered CHOP regime (cyclophosphamide $=750 \mathrm{mg} / \mathrm{m}^{2}$, vincristine $=1.4 \mathrm{mg} / \mathrm{m}^{2}$, adriamycin $=50 \mathrm{mg} / \mathrm{m}^{2}$ on day 1 and oral prednisolone $=100 \mathrm{mg}$ for 5 days). Patient was administered two cycles of CHOP regime at 21 days interval. After two cycles, no clinical improvement was noticed and thus patient was classified as refractory NK/T cell lymphoma. Thus, he was switched to SMILE regime (injection methotrexate $2 \mathrm{~g} / \mathrm{m}^{2}$ on day 1 , with leucovorin $15 \mathrm{mg}$ iv 6 hourly on day 2, 3, 4, injection ifosfamide $1500 \mathrm{mg} / \mathrm{m}^{2}$ on day 2, 3, 4 with mesna support, injection etoposide $100 \mathrm{mg} / \mathrm{m}^{2}$ on day 2, 3, 4, dexamethasone $40 \mathrm{mg} /$ day on day 2, 3, 4 orally and injection L-asparaginase $6000 \mathrm{U} / \mathrm{m}^{2}$ on day 8, 10, 12, 14, 16, 18, 20 along with GCSF support starting on day 6). The patient showed significant improvement to therapy [Figure 1b]. The patient was administered second cycle after 28 days.

\section{DISCUSSION}

Extranodal NK/T-cell lymphoma of nasal type has been formerly termed as angio-centric lymphoma, lethal midline granuloma, malignant midline reticulosis and polymorphic reticulosis among various literatures. ${ }^{[6,7]}$ The disease is more common among young and male population. There is specific tendency to involve nasal cavity, nasopharynx, oropharynx, tonsils and Waldeyer's ring, though there are documented reports of skin, gastrointestinal, spleen, kidney and breast involvement. For such cases, term "nonnasal NK/T-cell lymphoma" is coined and these are considered as clinically more aggressive. Rarely, there is widespread systemic involvement along with dissemination to peripheral blood and bone marrow. These cases are termed as NK/T-cell leukemia and had a catastrophic course with survival reported in weeks only. ${ }^{[8]}$

The disease is reported among all age groups (6-86 years) with more common in middle-age group. There is male predominance with a ratio of male:female being $2: 1$. Systemic symptoms as fever, night sweats and weight loss are often absent in the majority of patients leading to delay of diagnosis. The typical presenting features are limited to local symptoms as nasal obstruction, epistaxis, purulent rhinorrhea and sore throat. These lead to delay in arrival of correct diagnosis. The disease is locally invasive in approximately $50 \%$ of patients leading to complications in the form of nasal septum and palate perforation. Occasionally, it can involve orbital bone. Bone marrow involvement is rare. Regional lymph nodes may be involved in $40 \%$ of patients. Despite limited invasive disease in the majority of patients, serum LDH levels are increased..$^{[2,3]}$

Staging is done on the basis of local invasiveness. T1-weighted disease is defined as tumor restricted to one site with or without bony invasion; T2weighted invades two subsites in a single region within nasoethmoidal complex with or without bony invasion; T3-weighted invades floor of orbit, maxillary sinus, palate or cribriform plate; T4-weighted invades
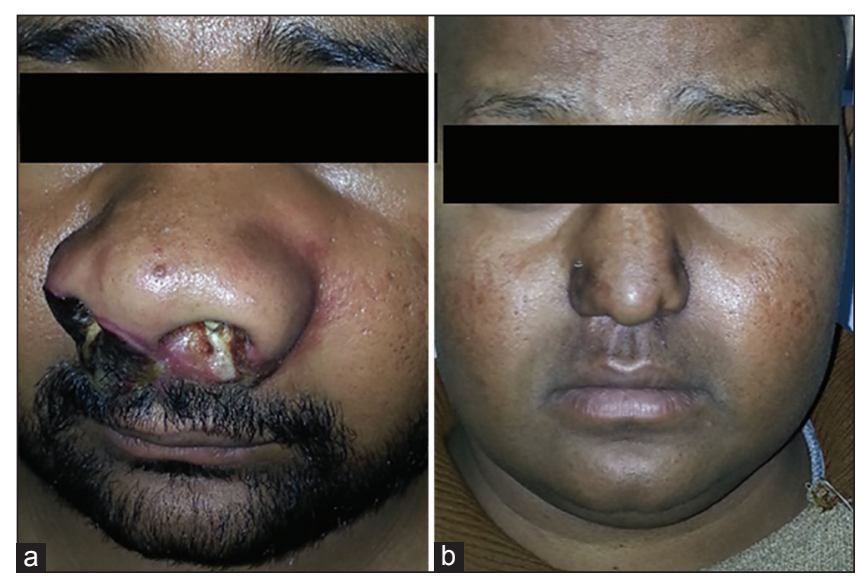

Figure 1: (a) Clinical photograph of the patient at the time of presentation and (b) patient after two cycles of SMILE regime

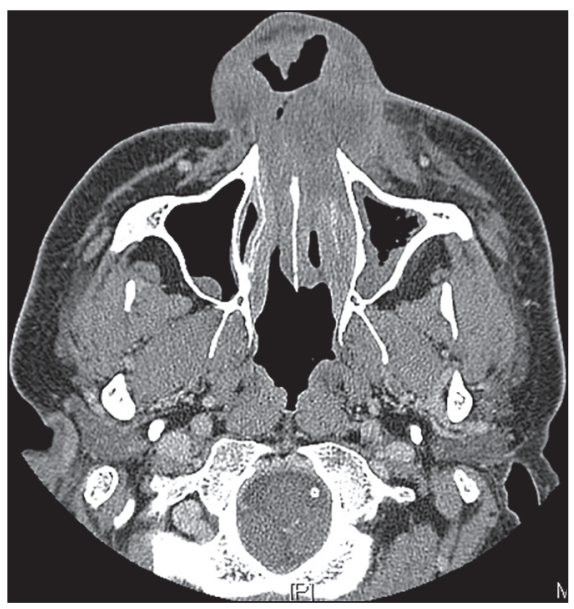

Figure 2: Computed tomography showing diffuse soft tissue thickening involving $\mathrm{b} / \mathrm{l}$ nasal vestibule, nasal walls and nasal septum predominantly anterior part

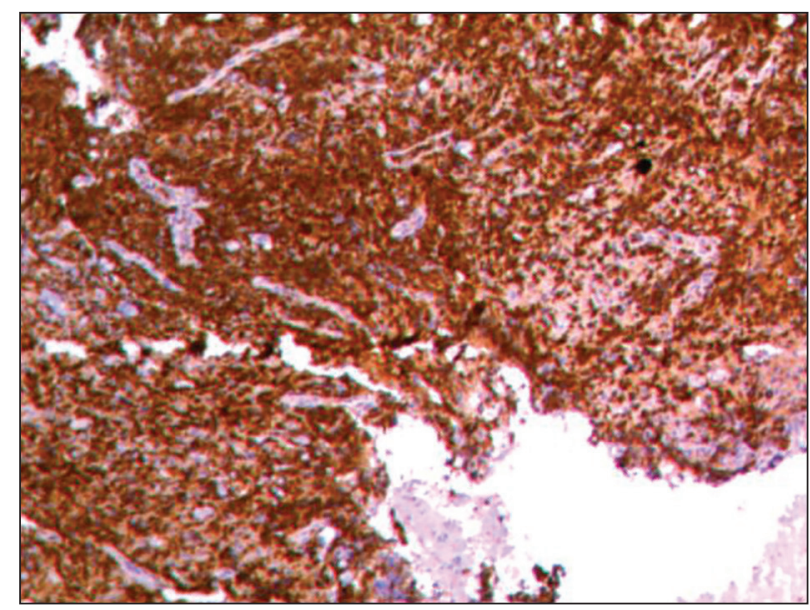

Figure 3: Microscopic features showing extensive necrosis and medium-sized lymphoid cells with hyperchromatic nuclei and CD3 immunohistochemistry positive

anterior orbital contents, skin of nose or cheek, minimal extension to anterior cranial fossa, pterygoid plates, sphenoidal or frontal sinuses, orbital apex, dura, brain, middle cranial fossa, nasopharynx, or clivus. 
Histo-pathologically, lymphoma cells are small to medium sized cells having pale cytoplasm with azurophilic granules admixed with eosinophils, plasma cells, and histiocytes. These infiltrates may show angio-centricity and angio-destruction leading to coagulative necrosis. On immunohistochemistry, lymphoma cells are typically $\mathrm{CD} 2^{+}$, cytoplasmic $\mathrm{CD}^{+}$, surface $\mathrm{CD} 3-$ ve, CD56+ve. Some cells also express CD16, perforin, granzyme B, T-cell intracellular antigen-1. These cells are infected by EBV and EBV-encoded RNA is invariably present among patients of Extranodal NK/T cell Lymphoma of Nasal type (ENKTLN). Studies have revealed that EBV RNA levels co-relate with the tumor load. However, there is a rare type, termed as T-cell part of $\mathrm{NK} / \mathrm{T}$-cell lymphoma characterized by $\mathrm{CD} 2^{+}$, cytoplasmic CD3+ve, EBV+ve but CD56-ve. Our patient belongs to same subtype of the rare part. ${ }^{[2,3,9]}$

Being a rare disease, treatment strategies are yet not formulated. Concurrent chemoradiation is standard approach. ${ }^{[10]}$ However, response to therapy is poor as these lymphomas express P-glycoproteins resulting in multi-drug resistance phenotypes. For recurrent and extensive disease, various chemotherapy regime as SMILE, VIPD, GELOX, GOLD have been devised but there use as a guideline is yet not validated. ${ }^{[4]}$ For patients with $\mathrm{NK} / \mathrm{T}$-cell leukemia and advanced stage lymphoma, autologous hematopoietic stem cell transplantation is recommended.

\section{CONCLUSION}

Extranodal NK/T-cell lymphomas of nasal type are rare but clinically aggressive tumor. Their typical clinical features and use of histo-pathological specimen for diagnosis can lead to the recognition of disease entity at an early stage. This leads to earlier institution of therapy and improved prognosis.

\section{REFERENCES}

1. Chan J, Jaffe ES, Ralfkiaer E, Ko YH. Aggressive NK-cell leukaemia. In: Swerdlow SH, Campo E, Harris NL, Jaffe ES, Pileri SA, Stein H, et al., editors. World Health Organization (WHO) Classification of Tumors of Hematopoietic and Lymphoid Tissues. Lyon: IARC Press; 2008. p. 276-7.

2. Liang Q, Ye ZY, Su ZL, Lin HL, Shao CK, Lin SX, et al. Clinicopathologic study of 963 cases of mature T-cell and natural killer/T-cell lymphoma with respect to $2008 \mathrm{WHO}$ classification of lymphoid neoplasms. Zhonghua Bing Li Xue Za Zhi 2010;39:291-5.

3. Au WY, Weisenburger DD, Intragumtornchai T, Shigeo N, Won-Seog K, Ivy S, et al. International Peripheral T-cell Lymphoma Project. Clinical differences between nasal and extra-nasal natural killer/T-cell Lymphoma: A study of 136 cases from international peripheral T-cell Lymphoma project. Blood 2009;113:3931-7.

4. Tse E, Kwong YL. How I treat NK/T-cell Lymphomas. Blood 2013;121:4997-5005.

5. Yamaguchi M, Kwong YL, Kim WS, Maeda Y, Hashimoto C, Suh C, et al. Phase II study of SMILE chemotherapy for newly diagnosed stage IV, relapsed, or refractory extranodal natural killer (NK)/T-cell lymphoma, nasal type: The NK-Cell Tumor Study Group study. J Clin Oncol 2011;29:4410-6.

6. Suzuki R, Takeuchi K, Ohshima K, Nakamura S. Extranodal NK/T-cell lymphoma: Diagnosis and treatment cues. Hematol Oncol 2008;26:66-72.

7. Wood PB, Parikh SR, Krause JR. Extranodal NK/T-cell lymphoma, nasal type. Proc (Bayl Univ Med Cent) 2011;24:251-4.

8. Kwong YL. The diagnosis and management of extranodal NK/T-cell lymphoma, nasal-type and aggressive NK-cell leukemia. J Clin Exp Hematop 2011;51:21-8.

9. Sassi LM, Schussel JL, Stramandinoli RT, Zanferrari FL, Skare NG, loshii S. Aggressive nasal extranodal NK/T cell lymphoma: Case report. Cancer 2011;2:1634.

10. Yamaguchi $M$, Tobinai $K$, Oguchi $M$, Ishizuka N, Kobayashi $Y$, Isobe $Y$, et al. Concurrent chemoradiotherapy for localized nasal natural killer/T-cell lymphoma: An updated analysis of the Japan clinical oncology group study JCOG0211. J Clin Oncol 2012;30:4044-6.

How to cite this article: Varshney AN, Patidar R, Malhotra M, Behera $M$, Nagar M, Kataria SP. Extranodal NK/T-cell lymphoma of the nasal type with predominant T-cell markers: A rare subtype of rare disease entity. Int J Med Public Health 2015;5:378-80.

Source of Support: Nil, Conflicts of Interest: None declared. 